MAX-PLANCK-INSTITUT FÜR WISSENSCHAFTSGESCHICHTE

Max Planck Institute for the History of Science

2013

PREPRINT 437

Jürgen Renn

Schrödinger and the Genesis of Wave Mechanics 



\title{
Schrödinger and the Genesis of Wave Mechanics
}

\author{
Jürgen Renn
}

The story of Erwin Schrödinger and of his contributions to quantum physics has been told many times. They indeed represent one of the most fascinating subjects in the history of science. But is there anything new to say about this story? At the Max Planck Institute for the History of Science and at the Fritz Haber Institute, both in Berlin, we have begun, in the context of a joint research project on the history and foundations of quantum physics, to carefully study once again the notebooks in which Schrödinger left traces of his pathbreaking research. And parallel to the pursuit of a comprehensive review of the emergence of quantum physics, we are also investigating more broadly the contexts in which this development took place. Against this background, new questions arise and old questions appear in a new light. For instance, what exactly was the relation between Schrödinger's breakthrough and the contemporary efforts by Werner Heisenberg and his colleagues to establish a new quantum mechanics? How can one explain, from a broader historical and epistemological perspective, the astonishing simultaneity and complementarity of these discoveries? Based on the work so far accomplished in our research project, it is to these questions that the present paper ${ }^{1}$ attempts to give new answers. ${ }^{2}$

But let us proceed in due order, beginning with a very short reminder of who Erwin Schrödinger was. Apart from being one of the most important scientists, he was probably also one of the most sensitive and educated persons of his time. He was born in 1887 in Vienna, studied there, and then was appointed to a professorship in Zurich in 1921. There he wrote his famous works on wave mechanics in 1926. In 1927 he succeeded Max Planck as the Chair for Physics in Berlin, but resigned his professorship in 1933 upon the National Socialists' accession to power. In the same year he learned that he had been awarded the Nobel Prize for Physics. He spent his years of exile in Oxford and in Dublin. In the Irish capital he wrote the famous book What is Life?, which was to play a decisive role in the development of molecular biology. In 1955 Schrödinger returned to Vienna, where he died in 1961. He was buried in Alpbach, amidst the Tyrolean Alps, where the equation bearing his name still adorns his tombstone today (see Fig. 2). ${ }^{3}$

The Schrödinger equation, postulated in 1926, is a key equation of quantum

\footnotetext{
${ }^{1}$ This paper will be published in 2013 in Erwin Schrödinger - 50 Years After. Wolfgang L. Reiter and Jakob Yngvason, eds. ESI Lectures in Mathematics and Physics. European Mathematical Society Publishing House, Zürich.

${ }^{2}$ See, in particular, (Duncan and Janssen, 2007a,b; Joas and Lehner, 2009).

${ }^{3}$ There are several book-length biographies of Erwin Schrödinger (Hoffmann, 1984; Moore, 1989, 1994) and further works on his life and science (Scott, 1967; Mehra and Rechenberg, 1987a,b). Schrödinger's letters concerning wave mechanics and the interpretation of quantum mechanics have recently been edited by Karl von Meyenn (2011).
} 


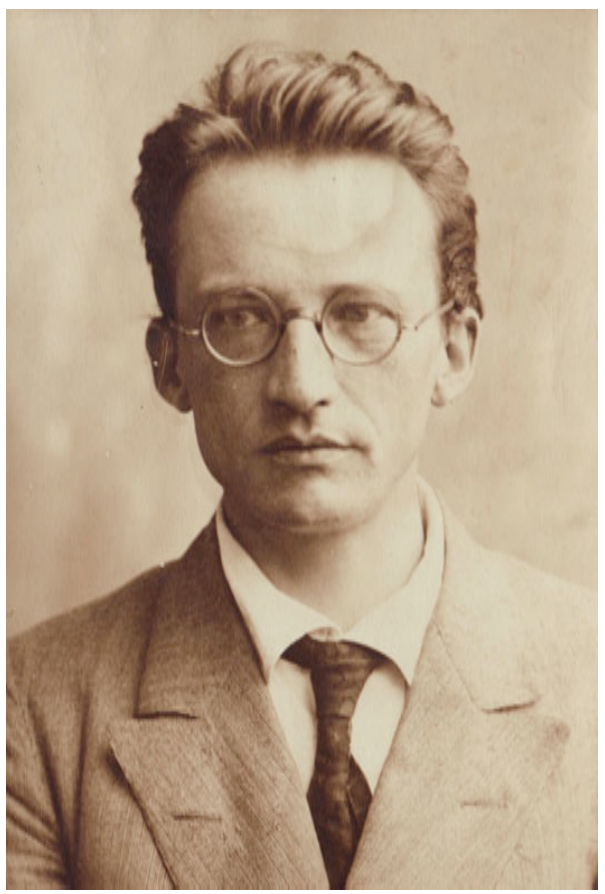

Abbildung 1. Erwin Schrödinger (1887-1961), ca. 1926. By permission of R. Braunizer.

physics. Arnold Sommerfeld once referred to it as "the most remarkable of all remarkable discoveries of the 20th century." When Max Planck held Schrödinger's second publication in his hands, he related to Schrödinger on a post card:

I am reading your communication in the way a curious child eagerly listens to the solution of a riddle with which he has struggled for a long time, and I rejoice over the beauties that my eye discovers, which I must study in much greater detail, however, in order to grasp them entirely. ${ }^{4}$

With reference to the origin of the Schrödinger equation, the American Nobel laureate Richard Feynman noted:

Where did we get that [Schrödinger's equation] from? Nowhere. It is not possible to derive from anything you know. It came out of the mind of Schrödinger, invented in his struggle to find an understanding

\footnotetext{
${ }^{4}$ Planck to Schrödinger, 2 April 1926. Translation from (Meyenn, 2011, p. 206): "Ich lese Ihre Abhandlung, wie ein neugieriges Kind die Auflösung eines Rätsels, mit dem es sich lange geplagt hat, voller Spannung anhört, und freue mich an den Schönheiten, die sich dem Auge enthüllen, die ich aber noch viel genauer im einzelnen studieren muß, um sie voll erfassen zu können."
} 


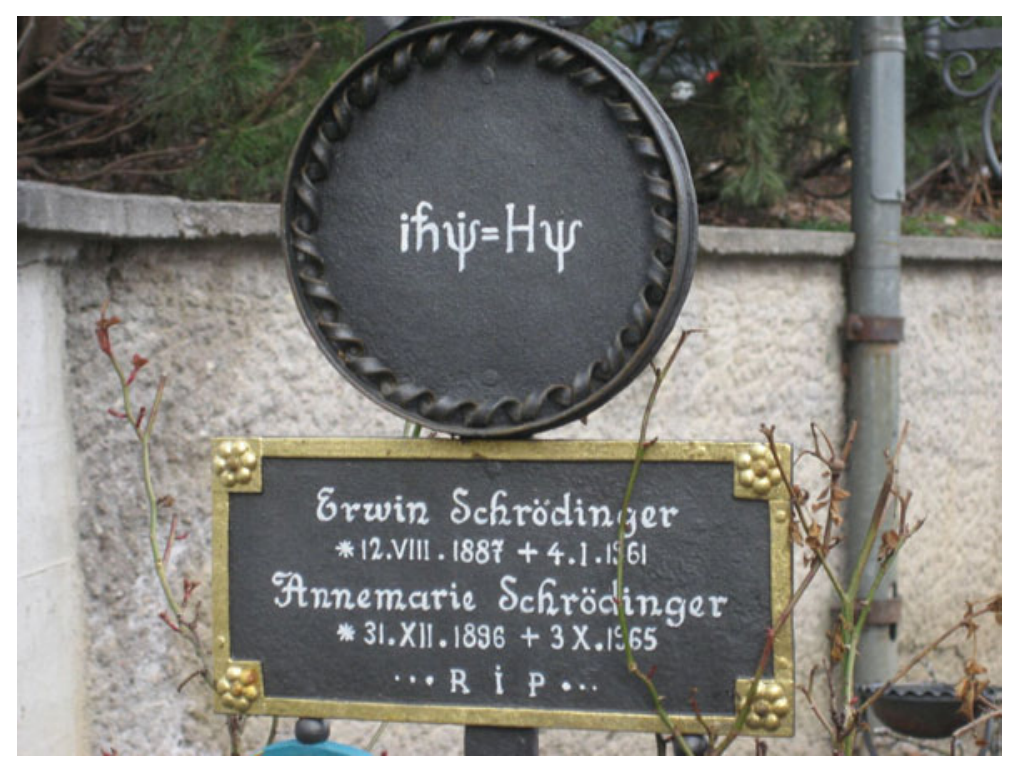

Abbildung 2. Tombstone of Annemarie and Erwin Schrödinger (1887-1961) with the Schrödinger equation $i \hbar \dot{\psi}=H \psi$ in modern notation. Photo by C. Joas, 2008.

of the experimental observation of the real world (Feynman et al., 1965, chapter 16, p. 12).

For an historian, this answer is unsatisfying. What exactly was the knowledge on which the Schrödinger equation was based? If it were just some contemporary experimental findings that it describes, how come then that this equation serves to this day in accounting for ever new phenomena that could not have been known to Schrödinger? And what was going on in Schrödinger's mind, on which intellectual resources did he draw to formulate his consequential equations?

In the following, we shall review, in a rather non-technical way, the genesis of the Schrödinger equation with the aim to contribute to a better understanding of one of the great upheavals in our scientific world view, as well as of the role that fell to Erwin Schrödinger in these events.

The Schrödinger equation supplies the foundation for understanding atomic physics and the chemical bond. It significantly changed our view of the constitution of matter and describes basic properties of the world as we understand them today. At the same time, even today it still challenges our thinking, in terms of not only physics and mathematics, but also natural philosophy. And yet the Schrödinger equation is a simple equation. Admittedly, it is not quite as simple as Einstein's famous formula $E=m c^{2}$. But the physics behind it is, in principle, even simpler.

The Schrödinger equation is a wave equation that describes material processes 
as wave processes. Wave phenomena like sound waves or light waves had been known for a long time. What was surprising was that even matter itself would allow itself to be described as such a wave phenomenon, that states of matter could overlap each other like vibrational states, and that there could be something like diffraction, interference or standing waves in matter as well, in short, that matter behaves like light in many respects.

But this thought was not entirely new, either. The development of quantum theory had begun a quarter of a century before with the discovery that electromagnetic radiation, like light, behaves under certain conditions as if it consisted of particles. Thus Einstein, in his light quantum hypothesis of 1905, had attempted to explain Planck's law of radiation and the photoelectric effect (Einstein, 1905). Since then the indications in favor of such a wave-particle dualism had steadily increased. Of course, all of the experiments that had led to the acceptance of the wave theory of light at the beginning of the 19th century, namely the phenomena of diffraction and interference mentioned above, were still valid, and still spoke in favor of wave theory. ${ }^{5}$

But more recent experiments like the photoelectric effect, that is, the release of electrons from metals through irradiation with high-frequency light; or the socalled Compton effect, that is, the scattering of X-rays by electrons in solids, could best be explained by the assumption of indivisible energy packets, known as the quanta of radiation. These behave like small billiard balls that possess a certain energy and a certain momentum. Neither could the surprising fact that the effect of radiation does not depend on its intensity, but on its color, such that electrons can be released only by high-frequency light, while low-frequency light has no effect no matter how strong it is, be explained by classical wave theory. This relation between energy and the color or frequency of radiation is given instead by a formula dating back to Planck, according to which the radiation energy $E$ is proportional to its frequency $\nu$, where the proportionality constant is Planck's quantum of action $h$, thus

$$
E=h \nu .
$$

Therefore, the higher the frequency of light, the greater the energy of the corresponding light quantum.

If light exhibits such a duality of wave and particle properties, why should this not also be the case for matter? Einstein's formula $E=m c^{2}$, where $m$ is the mass and $c^{2}$ the square of the speed of light, states that mass and energy are merely different manifestations of the same quantity: mass corresponds to energy and energy corresponds to mass. So if, according to Planck's equation $E=h \nu$, each energy is also associated with a certain frequency, then one need only combine both equations to happen upon the idea that every mass is also associated with a frequency, or more correctly, a wave phenomenon. The French physicist Louis de Broglie had arrived at this admittedly speculative thought in his dissertation

${ }^{5}$ For a further discussion, see (Wheaton, 1983; Büttner et al., 2003). 


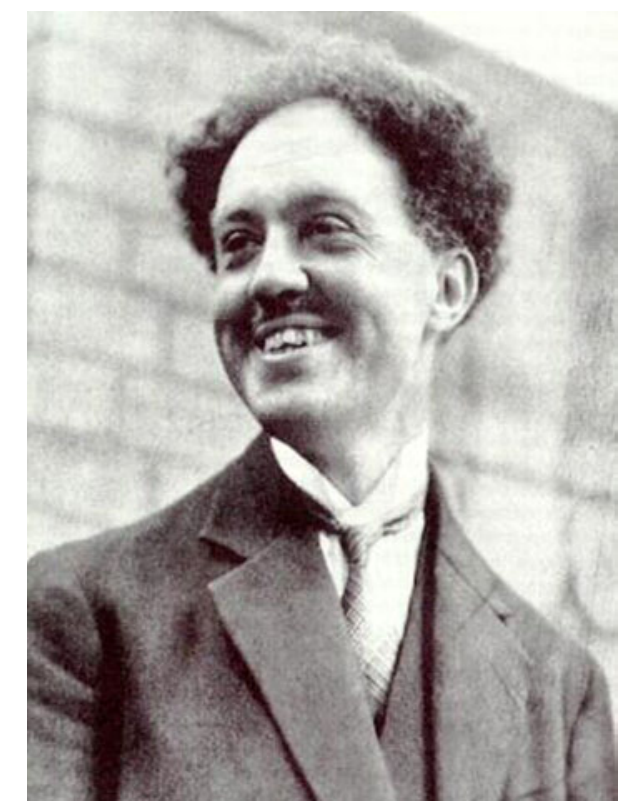

Abbildung 3. Louis de Broglie (1892-1987).

of 1924 (de Broglie, 1924). ${ }^{6}$ In order to supplement the wave picture of matter, he used, in addition to Planck's relation between energy and frequency, another relation that was just as simple: one between wavelength $\lambda$ and momentum $p$ :

$$
\lambda=\frac{h}{p} .
$$

Not only did this yield the possibility of translating completely the mechanical quantities energy and momentum into the wave quantities frequency and wavelength, it also offered a provisional solution to a fundamental puzzle of atomic physics.

The spectra of the chemical elements had been known since the 19th century. Spectra are like fingerprints that allow elements to be recognized on the basis of which colors of light they emit and absorb. The frequencies of this characteristic light had to be linked with the internal structure of the atoms, but for a long time it was not understood how. Even when experiments allowed ever more conclusions about this inner structure to be drawn, and when it became clear that the small charged particles, the electrons, played an important role in this process, it remained a mystery how their movement could generate or absorb the radiation

\footnotetext{
${ }^{6}$ See (Kubli, 1970) and (Darrigol, 1986).
} 
visible in the spectra. ${ }^{7}$ One could certainly imagine that the atom is structured like a small solar system, with the negatively charged electrons revolving on different orbits around a positively charged nucleus. But there was no way the orbital frequencies on these electron paths could have anything to do with the emitted or absorbed radiation.

Against this backdrop, the Danish physicist Niels Bohr made a radical proposal in 1913 (Bohr, 1913). ${ }^{8}$ He simply assumed that the frequency of the radiation emitted by an atom had nothing to do with the mechanical motion of its electrons, but depended instead on the energy difference between the various orbits. An atom should emit or absorb light only if an electron jumps from one orbit to another. The frequency of the light emitted or absorbed should then be defined by Planck's relation between energy and frequency, that is, by $E=h \nu$. This may have been no more than wild speculation, but it was sufficient to explain key properties of the spectra. What Bohr could not explain, however, were the basic properties of his model. Why, for instance, should the electrons be able to move only on certain orbits with precisely determined energies, why are these orbits stable, and why should atoms emit or absorb radiation only when their electrons jump back and forth between these orbits? These assumptions were justified provisionally only by the success of their application, but otherwise remained a mystery.

This is where the above-mentioned dissertation by de Broglie picked up around ten years later. De Broglie conceived matter to be linked with a wave phenomenon, arguing that the electron orbits in Bohr's model were stable because they corresponded to periodic waves. Just as for a vibrating string, a resonance effect was involved for electron motion, too, such that the wave returns back to itself along the orbital path. Only orbits on which this happens are stable. With this interpretation de Broglie succeeded in explaining the discreteness of a quantum phenomenon, that is, the occurrence of isolated orbits with certain energy levels rather than a continuum of possible orbits and energies, by resorting back to a well-known phenomenon of classical wave physics, and without having to introduce any additional assumptions along the lines of quantum jumps. And thus the idea of wave mechanics was born.

Einstein soon picked up on this idea, addressing it briefly in an entirely different context, the theory of gases (Einstein, 1924). This is where Schrödinger first encountered the idea of a wave theory of matter in 1925. The first work in which he himself dealt with the subject, even before formulating his famous equation, is also dedicated to gas theory (Schrödinger, 1926a). As de Broglie before him, he also used the wave conception so that he could render unnecessary the presumption of a mysterious quantum property, in this case that of a mysterious statistics of quantum gases, ${ }^{9}$ and instead make the properties of such gases comprehensible on the basis of classical statistics. ${ }^{10}$

\footnotetext{
${ }^{7}$ See (Jungnickel and McCormmach, 1986).

${ }^{8}$ See also (Heilbron and Kuhn, 1969).

${ }^{9}$ That is, the so-called Bose-Einstein statistics.

${ }^{10}$ That is, Maxwell-Boltzmann statistics.
} 


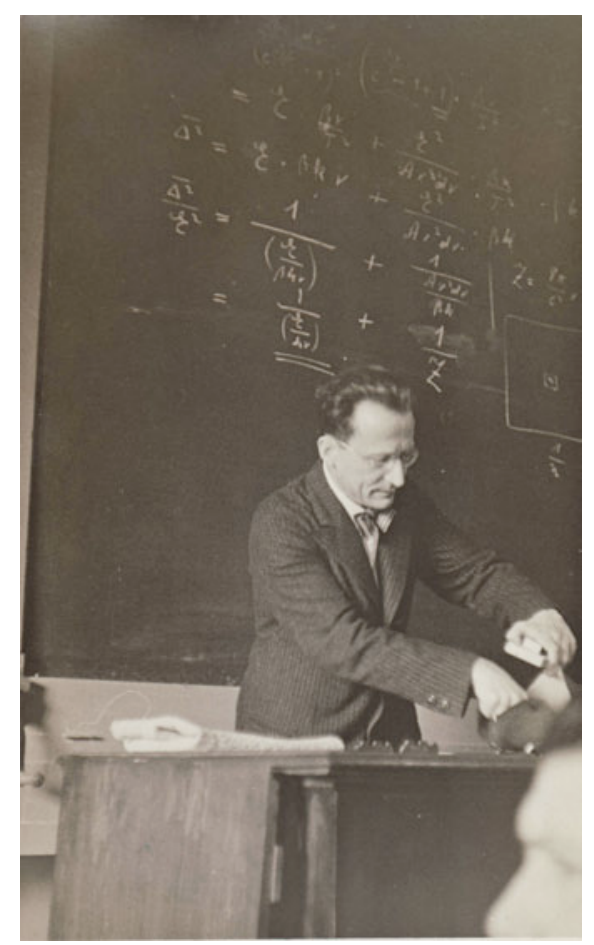

Abbildung 4. Erwin Schrödinger (1887-1961) lecturing. By permission of R. Braunizer.

From here, after all, it was no longer far to the Schrödinger equation-or so it may seem in retrospect. As discussed, the conception of matter as a wave had already yielded considerable successes; in particular, it made it possible to explain the strange discreteness of quantum states, that is, the occurrence of only certain values of energy, as resonance phenomena of vibrations. What was still missing was - obviously - a wave equation. But wave equations were certainly well known in classical physics, too, especially in wave optics. Take, for instance, the simplest wave equation, which describes the spatial distribution of the amplitude of a wave, $\psi(x)$, at a fixed point in time

$$
\frac{\partial^{2}}{\partial x^{2}} \psi(x)+\frac{4 \pi^{2}}{\lambda^{2}} \psi(x)=0
$$

Now replace the wavelength $\lambda$ appearing in this equation with momentum $p=h / \lambda$, in accordance with the simple rule stated by de Broglie (Eq. (2)):

$$
\frac{\partial^{2}}{\partial x^{2}} \psi(x)+\frac{4 \pi^{2} p^{2}}{h^{2}} \psi(x)=0 .
$$


Finally, express the momentum as a function of kinetic energy using $E_{k i n}=$ $p^{2} / 2 m=E-V$, such that $p=\sqrt{2 m(E-V)}\left(E=E_{k i n}+V\right.$ is the total energy, where $E_{k i n}$ is the kinetic and $V$ the potential energy):

$$
\frac{\partial^{2}}{\partial x^{2}} \psi(x)+\frac{8 m \pi^{2}(E-V)}{h^{2}} \psi(x)=0 .
$$

And voilà - there it is, the famous Schrödinger equation! $!^{11}$ The quantity $\psi(x)$ is called the wavefunction in wave mechanics.

Thus, no new mathematics at all is necessary to formulate the Schrödinger equation, and no new physical assumptions aside from the known rule by de Broglie, which is in principle only an obvious extension to Planck's relation between energy and frequency, that is, of $E=h \nu$. "The idea of your work testifies to genuine ingenuity!" Einstein wrote in the margin of a letter to Schrödinger. ${ }^{12}$

One might respond: but that cannot have been the whole story, what is then so special about this equation that it has become the foundation of atomic physics and has earned Schrödinger a Nobel prize; if one is bold, one may even ask what is supposed to have been so special about its formulation? Anyone could have come up with that! What is more, the only physics problem that Schrödinger solved in his first work was the calculation of the spectrum of the hydrogen atom, that is, one of the problems for which quantum theory already offered various solutions.

If one is skeptical about this achievement by Schrödinger, to the extent that I have described it so far, one finds oneself in the best of company. Even some of Schrödinger's contemporaries questioned whether the new wave mechanics would last any longer than a salon perm. Werner Heisenberg, for instance, reacted dismissively. Just half a year before he had made a proposal of his own for the establishment of quantum mechanics, for which he, too, was awarded the Nobel Prize. In a letter to the physicist Wolfgang Pauli he passed the following judgement on Schrödinger:

Many thanks for your wonderful book, [...] reading it was real recreation after Schrödinger's lectures here in Munich. As nice as Schrödinger is personally, I find his physics at least as strange: when you hear it you feel 26 years younger. ${ }^{13}$

\footnotetext{
${ }^{11}$ This is the time-independent (or stationary) Schrödinger equation. To our knowledge, this derivation was first presented by Born in July 1926 (Born, 1926b, p. 811-812). See also (Wünschmann, 2007; Ludwig, 1969). Note that Schrödinger's own derivation proceeded along a different path (Joas and Lehner, 2009). See also (Gerber, 1969; Kragh, 1982; Wessels, 1983) and the discussion below.

${ }^{12}$ Einstein to Schrödinger, 16 April 1926. Translated after (Meyenn, 2011, p. 214): "Der Gedanke Ihrer Arbeit zeugt von ächter Genialität."

${ }^{13}$ Heisenberg to Pauli, 28 July 1926. Translated from (Pauli, 1979, p. 336-337): "Haben Sie vielen Dank für Ihr schönes Buch, in dem ich zwar kritisch und unnachsichtig, aber doch mit viel Freude gelesen habe. Es ist eben eine exakte Darstellung der physikalischen Zusammenhänge, die vor dem Durcheinander des letzten Jahres bekannt waren, und seine Lektüre war mir eine wahre Erholung nach Schrödingers Vorträgen hier in München. So nett Schr[ödinger] persönlich ist, so merkwürdig find' ich seine Physik: man kommt sich, wenn man sie hört, um 26 Jahre jünger vor."
} 


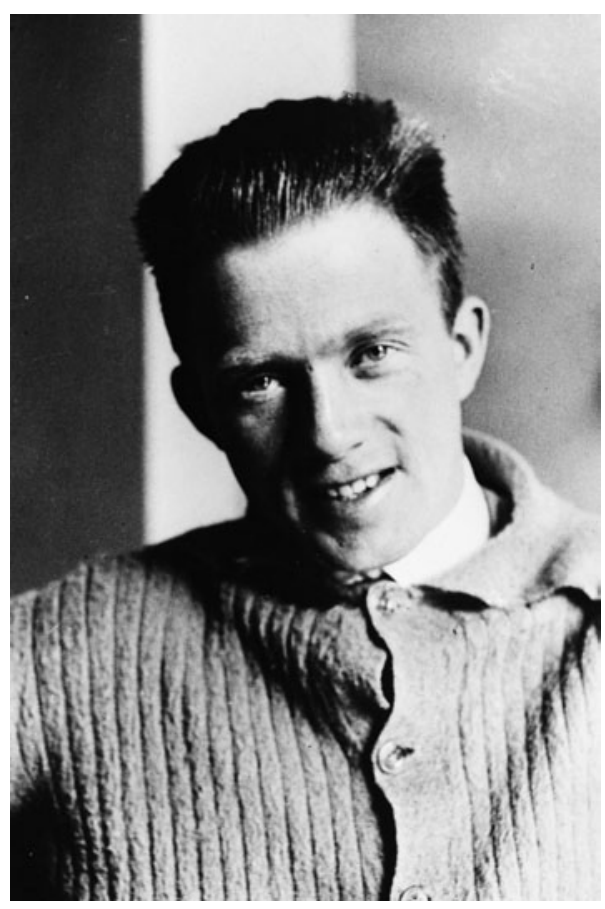

Abbildung 5. Werner Heisenberg (1901-1976).

Yet for Heisenberg, who was 25 at the time, feeling "26 years younger" in the face of Schrödinger's theory meant that he must associate it with the dawn of quantum theory, the age of the classical physics of the 19th century. In the same letter he did, in fact, call Schrödinger's physics "classicist" and accuse him of having made it too simple by "throwing overboard" all substantial quantum effects. Heisenberg, on the other hand, had come to his own theory, which later became known as matrix mechanics, by occupying himself laboriously and step by step with these quantum problems.

A crucial issue, which ultimately showed Heisenberg the way, was the problem of optical dispersion, namely the fact that diffraction in a certain material was dependent on the color of light. ${ }^{14}$ For this an appropriate formula had been found back in the 19th century, using a model of the atom based on classical physics to explain dispersion as an effect of the incoming radiation on the electrons, a covibration that disturbs their natural orbits. It had just recently turned out, however, that the emission and absorption of radiation could not be described by a classical model, but only by a quantum theoretical model of the atom like the one by

\footnotetext{
${ }^{14}$ See (Duncan and Janssen, 2007a,b).
} 
Bohr. Yet in such a model there could no longer be any covibrations of electrons nor any perturbation of their orbital paths, for in this case the frequency of the emitted and absorbed radiation is not at all dependent on the orbital motion of the electrons, but rather on their quantum jumps between the various paths. The supposedly long solved problem of dispersion thus had become a genuine quantum puzzle, which somehow seemed to make it necessary to link the established classical views on the nature of diffraction of light with its undeniable quantum properties. Such transitional problems between classical and quantum physics existed at various junctures in the field of physics at the time, and they proved to be especially productive, for such problems could show the way to expand classical physics by suggesting special additional assumptions in order to solve the quantum riddles.

Indeed, before 1925 the connection between classical physics and the new quantum physics was conceived rather generally as merely extending the former by adding supplementary quantum conditions. ${ }^{15}$ According to this view, not all of the theoretically possible solutions to a mechanical problem were possible any longeronly those that obeyed these additional quantum conditions, which typically boiled down to allowing certain physical quantities to equal only multiples of Planck's quantum of action $h$. Therein lay the essence of the so-called "old quantum theory," which was actually no theory at all, but an accumulation of calculation and translation rules to extend classical physics. Despite many obscurities and contradictions, this older quantum theory dominated the thinking of physicists between 1913 and 1925, simply because there was no alternative and, as it appeared to some, perhaps there never would be one.

This school of thought was so fruitful, for one, because it was constantly occupied with new problems, some of which had been raised by new experiments; and second, due to the fact that transitional problems kept arising, which made it possible to modify results from classical physics in a targeted way so that they could yield solutions for quantum problems. For the emission of radiation with very low frequencies, for instance, Bohr's atomic model and its classical counterpart, in which the frequency of radiation really does depend on the orbital frequency of the electrons, yielded practically equal results. In 1916, Einstein was able to show that Planck's radiation law could be derived if it was assumed that the intensity of the radiation emitted by many Bohr atoms corresponds exactly to the intensity of classical radiation (Einstein, 1916a,b). Niels Bohr subsumed such correspondences under the somewhat vague term "correspondence principle" and systematically applied this heuristic principle in his search for solutions to quantum problems. ${ }^{16}$ In a sense, the correspondence principle had the basic function of restoring the classical connection between the radiation properties and periodicity properties of the atom, for which there was initially no natural place in Bohr's model.

The transitional problems that thus accumulated, some of which were true quantum problems, but others of which could be solved in part or in limiting

\footnotetext{
${ }^{15}$ See, e.g., (Darrigol, 1992b).

${ }^{16}$ See (Darrigol, 1992b).
} 
cases using established concepts of classical physics, expanded the catalogue of calculation and translation rules ever further. But they initially did not lead to a comprehensive and consistent scheme for translating from classical to a new quantum physics. Many problems, even quite central ones like the spectrum of the helium atom, proved inaccessible to any solution, no matter how elaborate the conversion. Thus there was talk of a crisis of the old quantum theory, ${ }^{17}$ which came to a head shortly before the time when Heisenberg and Schrödinger published their works.

Nevertheless this was not a crisis from the creative confusion of which a new paradigm ultimately rose like a phoenix from the ashes. The birth of the new quantum mechanics, in short, was no scientific revolution according to Thomas Kuhn's definition. Instead, what ultimately led to the resolution of the crisis was the consistent pursuit of the established strategy of the old quantum theory, and an especially sophisticated modification of classical physics, developed in order to solve a quite concrete physical problem. The pursuit of the tried-and-true strategy of old quantum theory consisted above all in the search for possibilities to "sharpen" Bohr's correspondence principle; this meant going beyond the use of this principle in establishing the classical limit of quantum-theoretical treatments, and rather to elaborate this principle into a translation rule that allowed the solution of a quantum problem to be found, starting from its classical formulation. Over and again this approach was surprisingly successful for individual quantum problems, giving hope from the outset that a comprehensive translation scheme ultimately could be achieved. However, the attempt to proceed from individual successful translations to divine such a generalized scheme experienced defeats as well. For instance, the physicist Max Born of Göttingen proposed in 1924 that a generalized quantum mechanics could be achieved by replacing the differential equations of classical physics with difference equations (Born, 1924), but this attempt failed.

In fact it was the concrete problem of dispersion that ultimately put Heisenberg on the right path. Back in 1924, Born had written clairvoyantly:

As long as one does not know the laws of how light affects atoms, and thus the connection between dispersion, atomic structure and quantum jumps, one will be all the more in the dark about the laws of interaction between multiple electrons in an atom. ${ }^{18}$

Indeed, we already discussed that dispersion represented a borderline problem that was best addressed by linking the considerations of classical physics with those based on quantum theory. At the same time it was important to do justice to the fact that while the radiation behavior of an atom had nothing to do with the classical orbital frequency of its electrons, an explanation of dispersion nevertheless

\footnotetext{
${ }^{17}$ See (Darrigol, 1992b). See also (Büttner et al., 2003).

${ }^{18}$ Translated from (Born, 1924, p. 379): "Solange man die Gesetze der Einwirkung des Lichtes auf Atome, also den Zusammenhang der Dispersion mit dem Atombau und den Quantensprüngen, nicht kennt, wird man erst recht über die Gesetze der Wechselwirkung zwischen mehreren Elektronen eines Atoms im Dunkeln sein."
} 


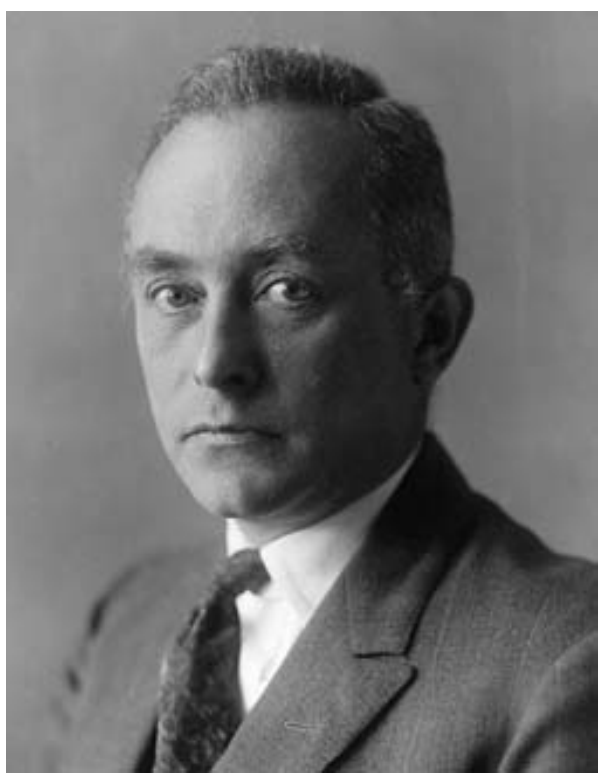

Abbildung 6. Max Born (1882-1970).

made some kind of covibration necessary, for otherwise it was practically impossible to understand why the classical explanation based on this assumption was so successful.

Rudolf Ladenburg, a physicist from Breslau, thus introduced the concept of "virtual oscillators," the frequencies of which corresponded to those of Bohr's quantum jumps, but which also were able to interact with incident radiation by resonating, that is, co-vibrating. ${ }^{19}$ At the same time, the success of introducing these auxiliary virtual oscillators, which, as we will see below, could potentially lead to the desired "sharpening" of the correspondence principle, also meant that the interior of the atom could not be conceived simply as a miniature planetary system; entirely new physical concepts were required instead. In the history of the theory of relativity, Lorentz's ad hoc assumption of a contraction of moving objects caused by the ether played a similar role. It, too, turned out to be the useful auxiliary construction of an invisible mechanism, which ultimately helped Einstein to find an explanation for the problems of the electrodynamics of moving objects on the deeper level of new concepts of space and time. ${ }^{20}$

But the key factor at this point was the possibility of expanding the theoretical approach to dispersion by adding ever more findings from quantum theory to this ad hoc assumption of virtual oscillators, up to the point where it finally amoun-

\footnotetext{
${ }^{19}$ See, e.g., (Duncan and Janssen, 2007a,b).

${ }^{20}$ See (Renn, 2006).
} 
ted to a stricter application of the correspondence principle. While no convincing theoretical model was achieved that could have taken the place of the planetary concept of the atom, the sharpening of the correspondence principle in the case of dispersion did yield a formula that corresponded to all experimental findings and thus could be understood as a translation, albeit a complicated one, of classical properties into quantum properties. But precisely the complicated character of this successful translation allowed far-reaching conclusions to be drawn, in the same way the famous Rosetta Stone's elaborate, multi-lingual texts in the 19th century allowed more to be learned about the then-undeciphered Egyptian hieroglyphs than the mere translation of individual signs, even though it was the names of the rulers that had revealed the first patterns to Champollion.

It was Werner Heisenberg who took the last, decisive step toward translation in July 1925, in his famous work, "Quantum-Theoretical Re-interpretation of Kinematic and Mechanical Relations" (Heisenberg, 1925). His point of departure was the dispersion formula. A method of formulating it in classical physics proceeded by way of what was called the Fourier series representation of the electron trajectory and its perturbations, that is, its portrayal as a superposition of harmonic oscillations. This method of representation was an established technique in classical physics, the origins of which extend all the way back to ancient astronomy, which likewise conceived of the complicated trajectories of the planets in the heavens as a superposition of uniform circular motions. For the classical dispersion formula certain very specific aspects of this Fourier series representation were decisive. The dispersion formula of quantum theory, in turn, as we saw above, could be formulated using the concept of virtual oscillators.

Accordingly, from this parallel between the classical and quantum theories of optical dispersion, a relation could be established between the partial aspects of classical Fourier series decisive for the dispersion formula and the virtual oscillators of quantum theory. More than a month before submitting his famous Umdeutung paper, Heisenberg wrote in a letter to Ralph Kronig:

The basic idea is this: In the classical theory, it suffices to know the Fourier series of the motion in order to calculate everything, not just the dipole moment (and the emission), but also the quadrupole moment and higher moments etc. [...]. It thus seems likely that also in quantum theory knowledge of the transition probabilities, or the corresponding amplitudes, yields everything. [...] The quintessence of this re-interpretation [Umdeutung] to me appears to be the fact that the arguments of the quantum-theoretical amplitudes have to be chosen such that they reflect the connection between the frequencies. [...] What I like in this scheme, is that it allows one to reduce all interactions of the atom with its surroundings to the transition probabilities (barring questions of degeneracy). For now I am, however, unsatisfied by the mathematical formalism. ${ }^{21}$

${ }^{21}$ W. Heisenberg to R. Kronig, 5 June 1925, translated from (Kronig, 1960, p. 23-24): "Der 
Heisenberg's insight into the relationship between the classical Fourier series representation and the virtual oscillators of quantum theory in the case of optical dispersion corresponded to a "sharpened" correspondence principle in the sense of a complete translation of the classical solution of a problem into the solution of the corresponding quantum problem. But using Fourier series expansion to solve the problem of dispersion had consequences that extended much further, for the Fourier series was a quite general mathematical instrument used to represent physical quantities. So if the translation of the partial aspects decisive for the dispersion formula could be successfully generalized into a Fourier series representation of any physical quantity, then the sought-for general scheme for translating classical physics into a new quantum mechanics would be found at long last.

It turned out that this generalized translation, which Heisenberg called "reinterpretation," resulted nearly inevitably from the demand that the classical Fourier series be modified so that the different oscillation frequencies occurring are composed in a way that corresponds to Planck's relation $E=h \nu$ between energy and frequency. From this it follows, as Bohr's atomic model illustrates, that the radiation of a certain frequency emitted due to a quantum jump from a higher orbital path to a lower one can be traced back to the different energies of these two orbital paths. It further follows that such opportunities to jump between the different orbits and the energy levels corresponding to these orbits can be composed such that only very specific sets of emission frequencies are possible and thus observable in atomic spectra. According to Heisenberg, these emission frequencies and their possible combinations, in turn, are incorporated into the modified quantumtheoretical Fourier series representation. These frequencies, however, could not be related to the orbital frequencies of electrons in the atom. As it turned out, the physical interpretation of the rules of Heisenberg's re-interpreted mechanics no longer hinged on such mechanical conceptions. Ultimately their justification was based on no descriptive physical model at all, but on their origination from a "sharpened" correspondence principle and its success in explaining concrete physical problems like that of optical dispersion.

This brings us to the crucial epistemological challenge of the genesis of quantum and wave mechanics. It seems to be a mystery how such different paths of thought as those of Heisenberg and Schrödinger could lead to perfectly-matching solutions of the quantum crisis. Even the mathematical formulation of the two solutions was completely different in the end, with partial differential equations in Schrödinger's

Grundgedanke ist: In der klassischen Theorie genügt die Kenntnis der Fourierreihe der Bewegung um alles auszurechnen, nicht etwa nur das Dipolmoment (und die Ausstrahlung), sondern auch das Quadrupolmoment, höhere Pole u.s.w. [...] Es liegt nun nahe, anzunehmen, dass auch in der Quanentheorie durch die Kenntnis der Übergangswahrscheinlichkeiten, oder der korrespondierenden Amplituden alles gegeben ist.[...] Das Wesentliche an dieser Umdeutung scheint mir, dass die Argumente der quantentheoretischen Amplituden so gewählt werden müssen, wie es dem Zusammenhang der Frequenzen entspricht. [.. . ] Was mir an diesem Schema gefällt, ist, dass man wirklich alle Wechselwirkungen zwischen Atom und Aussenwelt dann auf die Übergangswahrscheinlichkeiten reduzieren kann (von Entartungsfragen abgesehen). Nicht zufrieden bin ich zunächst mit der mathematischen Seite [...]." 
case and matrix calculus for Heisenberg, as would soon become clear in the context of further elaborating his re-interpretation in collaboration with Max Born and Pascual Jordan (Born and Jordan, 1925; Born et al., 1926).

For the physicist, this mystery, or at least the provocation it evokes, is resolved for the most part at the moment when the equivalence of these two approaches, that is Schrödinger's wave mechanics and Heisenberg's quantum mechanics, can be proven. This actually happened quite quickly. Unpublished calculations by Wolfgang Pauli and a further publication by Schrödinger (1926d) from the same year showed that the two theories could be mapped upon each other mathematically and in principle yielded the same physical results. ${ }^{22}$ From a historical point of view, however, this equivalence proof merely increases the challenge posed by the birth of quantum mechanics as a set of fraternal twins.

Why was it possible that Schrödinger's wave mechanics led to the same conclusions as Heisenberg's matrix mechanics, although the problem of dispersion, which had played such a key heuristic role in the latter, did not lie along Schrödinger's route to his equation? And why could matrix mechanics yield the same results for the spectrum of the hydrogen atom, although this problem, which had been at the center of de Broglies' and Schrödinger's wave mechanics from the outset, did not play a significant role in its formulation? In short, why did these two very different paths of thought ultimately arrive at the same destination? To these questions there are a number of obvious answers, including some from the standard repertoire of the history and philosophy of science. But only when we recognize that these standard answers are unsatisfactory, and why, does the parallel emergence of quantum mechanics along both paths allow deeper insights into the nature of this scientific breakthrough.

It is a fact that Schrödinger knew Heisenberg's theory before he formulated wave mechanics. Does this perhaps mean that wave mechanics emerged as a reformulation of a theory that was already known? Everything we know from the historical documents speaks against this version. Heisenberg's theory was indeed known to Schrödinger, but he found it so unappealing that the only thing about this alien theory that could have motivated his approach to wave mechanics was vehement rejection. Schrödinger himself writes - and this is the counterpart to the previously cited disparaging judgement of Schrödinger's solution by Heisenberg:

I am indeed unaware of a genetic connection to Heisenberg['s theory]. I knew of his theory, of course, but I felt discouraged, not to say repelled, by the methods of transcendental algebra, which appeared difficult to me, and by the lack of visualizability $\left[\right.$ Anschaulichkeit $\mid{ }^{23}$

\footnotetext{
${ }^{22}$ For a discussion of the equivalence proofs between matrix and wave mechanics and their mathematical rigor, see (Muller, 1997a,b, 1999; Perovic, 2008).

${ }^{23}$ Translated from (Schrödinger, 1926d, p. 735, footnote 2): "Eines genetischen Zusammenhanges mit Heisenberg bin ich mir durchaus nicht bewußt. Ich hatte von seiner Theorie natürlich Kenntnis, fühlte mich aber durch die mir sehr schwierig scheinenden Methoden der transzendenten Algebra und durch den Mangel an Anschaulichkeit abgeschreckt, um nicht zu sagen abgestoßen."
} 
Were the two theories perhaps merely two unfinished, but complementary halves of a greater whole - modern quantum mechanics - still in the process of emerging, which came into being only through the further developments and mathematical formulations of Born, Jordan, Dirac, Hilbert and finally von Neumann in 1932? Certainly, a great deal of evidence speaks for this: besides the unfinished character of both theories, especially the circumstance that what was most important about Schrödinger's theory, from today's perspective, was that it made the quantum states understandable, while Heisenberg's theory describes the physically observable quantities as mathematical operators to be applied to these states. On the other hand, from the very outset the two unfinished halves must have borne the potential for their integration, or at least for fitting them together, for otherwise Schrödinger's proof of equivalence would have been impossible, and neither would it have been conceivable that each of the two approaches was able to solve key problems like the hydrogen atom on its own and more or less independently of the other. ${ }^{24}$

Was it perhaps just harsh reality and its quantum character that forced the convergence of the two theories? After all, they both had to do with the same empirical knowledge, resulting from the contemporary experiments as well as from other, older empirical evidence. What speaks against this naïve-realistic response is that each of the two theories reflected only parts of this reality, while many other quantum aspects remained hidden, particularly the role of spin, which was still unclear at the time; statistical properties of quantum systems, relativistic effects, and the entire complicated aspect of the variety of manifestations of the physics of condensed matter, which was by no means entirely unknown at the time. How did it happen that both approaches, despite their essentially different points of departure, ultimately ended up recording the same part of reality, although the demarcation of this part, in the sense of a kind of non-relativistic quantum mechanics of single-particle systems without spin and statistics, could not even be formulated clearly without knowing the final outcome?

In the end the spontaneous Platonism of the natural scientist remains as a conventional explanation, that is, the conception that behind the apparent variety of phenomena is hidden a transcendental reality of mathematical ideas that have always existed independent of man. Was it perhaps the pre-established harmony of such mathematical structures that resulted in Schrödinger and Heisenberg, although they lifted different parts of the veil, ultimately having to discover the same secret, the Hilbert space structure, which, according to today's understanding, is what constitutes the mathematical essence of quantum mechanics? But even if that were the case, it would still remain astounding that this supposedly pre-existing mathematical structure had no essential heuristic function for either of the two

\footnotetext{
${ }^{24}$ Schrödinger explained the hydrogen spectrum and the Stark effect splitting in his first three communications as the key example for the application of his wave mechanics (Schrödinger, 1926b,c,e). Within matrix mechanics, the explanation of the hydrogen spectrum and the Stark effect splitting is due to Pauli (1926).
} 


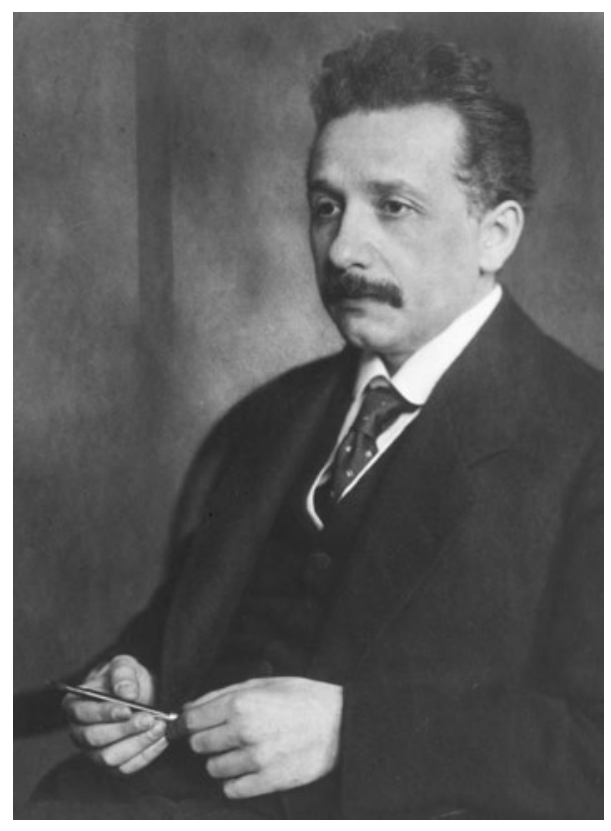

Abbildung 7. Albert Einstein (1879-1955).

theories and was not discovered at all until so long after they were formulated. ${ }^{25}$ The notion of a world of Platonic ideas, which guide knowledge so little in the real world, is not terribly convincing.

Therefore a different explanation seems in order, which one could call a genetic explanation. It has already been tried and tested in historical studies on the emergence of the theory of relativity. ${ }^{26}$ Indeed, this name seems quite fitting when one recalls the image of the fraternal twins used before. In the history of relativity theory there is a puzzle similar to that of the double birth of quantum mechanics, the paradox of missing knowledge. Today the general theory of relativity is the theoretical foundation of astrophysics and cosmology, and especially the explanation of gravitational lenses, black holes and the expanding universe, all of which are phenomena that were unknown back when the theory was formulated in the year 1915. At that time there were very few indications at all of deviations from Newton's theory that would recommend the development of a new theory of gravitation. So what was the empirical foundation upon which Einstein was able to formulate a theory that has stood up to all of the new-occasionally dramatic - advances in the insights of observational astronomy up to the present?

Historical studies have shown that this theory emerged from a transformation

\footnotetext{
${ }^{25}$ See (von Neumann, 1932).

${ }^{26}$ See (Renn, 2007).
} 
of the knowledge of classical physics. It started not with a new paradigm that was irreconcilable with old concepts, but with a reorganization of the store of knowledge already available. This reorganization had become necessary because of challenges, only some of which were conditioned directly by new empirical findings, but the majority of which arose through internal tensions in the body of knowledge of classical physics, which, for their part, were certainly the consequence of increased empirical knowledge. This can be illustrated best using the example of Einstein's equivalence principle and the corresponding mental model of an accelerated box. An observer in a closed, accelerated box without windows - often described as an elevator (see Fig. 8) - has an apple in his hand, which he then drops. The apple falls to the floor of the box. In principle, the observer cannot tell whether this falling motion is a consequence of the acceleration of the box, such that the apple is merely obeying its own inertia, or whether the box is not actually accelerated at all, but standing on firm ground such that the falling motion is caused by gravity. This simple thought experiment, which remains completely within the framework of classical physics, suggests that inertia and gravitation are similar in nature. In particular, it can be concluded from Einstein's equivalence principle that inertial forces occurring in accelerated systems, as in a carousel, for instance, are an expression of one and the same interaction between masses as gravitational forces. This conclusion yields a new perspective on classical physics, in which such forces do not actually have anything to do with each other.

But is it possible to re-formulate classical physics such that the similar nature of gravitation and inertia becomes the center of its conceptual foundation, rather than just appearing as a marginal and apparently coincidental by-product? Such a process of reorganization, in which a previously marginal element of a conceptual system becomes the center of a new one, may be called a "Copernicus process." ${ }^{27}$ It turns out that, if one combines the reorganization of classical physics in the light of Einstein's elevator thought experiment with the insights of special relativity about the relation of rulers and clocks in reference systems moving toward each other, basic insights of the theory of general relativity follow. In other words, this theory emerged from a reorganization of classical physics, which allowed the experiences stored in this field to be linked with new insights like those of the special theory of relativity, with as few losses and as little conflict as possible. The long and sustained stability of the theory of general relativity is rooted in the success of this networking of knowledge.

Quantum mechanics, too, emerged from such a transformation of the knowledge of classical physics. This knowledge incorporated not only a wealth of empirical knowledge, but also a wide variety of concepts and techniques that had accumulated over centuries. It is no coincidence that quantum mechanics still uses concepts like place, time, mass, momentum, and energy, and that its mathematical form still exhibits such a close relationship to the advanced formulations of classical mechanics like the Lagrangian and the Hamiltonian formalism. It emerged from the

${ }^{27}$ See (Renn, 2006, 2007). 


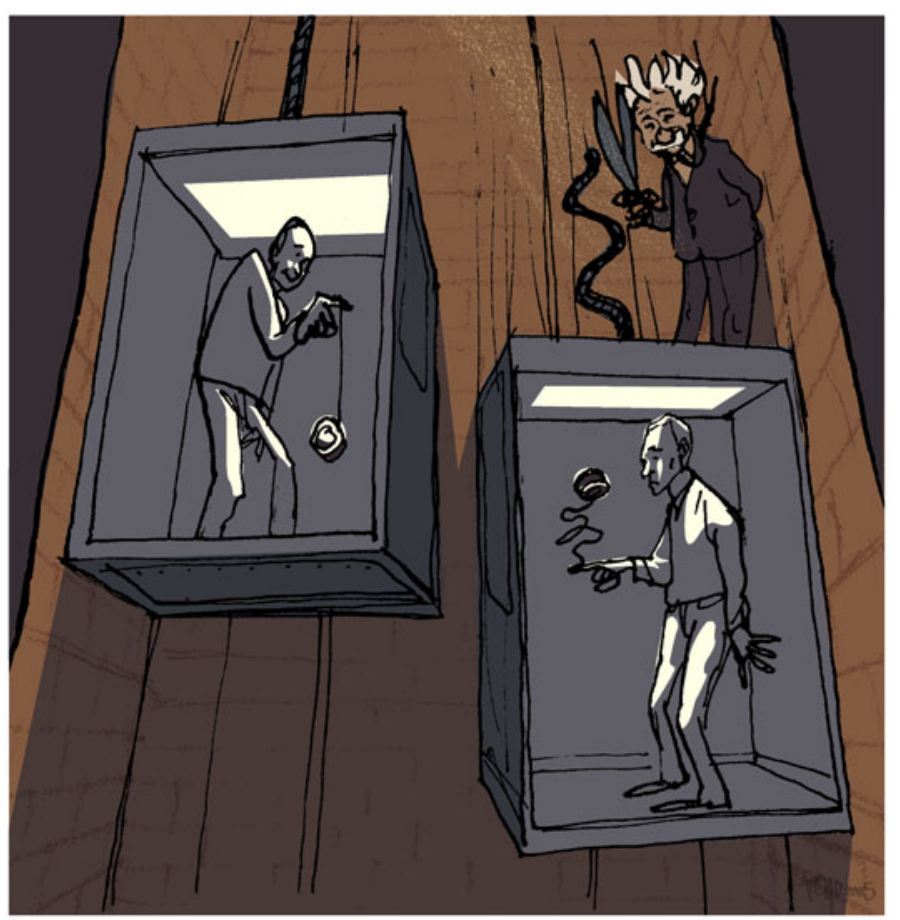

Abbildung 8 . The indistinguishability of gravitational and inertial forces, illustrated by the elevator thought experiment. By Laurent Taudin.

transformation of this mechanics. And its validity, too, is not conceivable without this genesis, for it rests, just as was the case for the general theory of relativity, not only on the specific observational and experimental knowledge that accompanied its emergence, but on the whole body of empirical knowledge that had supported the classical mechanics before it.

Quantum mechanics' parallels to the emergence of the general theory of relativity can be pursued even further, however, and ultimately even lead us to a solution to the twin paradox of its emergence. The new knowledge that was to be combined with the old mechanics expressed itself primarily through Planck's relation between energy and frequency and through the de Broglian counterpart, the relation between momentum and wavelength. In the old quantum theory, as we saw, this relation was, in a sense, merely grafted on to old mechanics - as an additional, auxiliary condition, which meant that only certain classical solutions were permitted. The counterpart from the history of relativity theory is the failed attempts to impose the demand of the special theory of relativity, that no physical effect may propagate faster than light, as an additional condition to the Newtonian 
theory of gravity. In contrast, Heisenberg's and Schrödinger's approaches can be regarded as successful variants of a reorganization of classical mechanics, in which Planck's relation makes direct contact with its fundamental concepts.

For Heisenberg's re-organization, this happened, as we saw, through the Fourier series representation of mechanical quantities, which includes frequencies whose behavior is then determined through the combination principle of spectra, which, in turn, is a consequence of Planck's relation. ${ }^{28}$ Schrödinger's re-organization, in turn, succeeded, as we also saw, through the translation of a classical wave equation into the basic equation of a new mechanics using de Broglie's relation between momentum and wavelength, which also constitutes a consequence of Planck's relation. Thus the two approaches essentially process the same knowledge and respond to the same challenge, that of integrating Planck's non-classical relation into the basic concepts of classical mechanics. From this genetic perspective it is thus no wonder that both arrived at results that fit together like a pair of gloves.

But why did Heisenberg and Schrödinger take such different paths, and what is the relationship between these paths? This question leads back to Schrödinger's formulation of wave mechanics and the extraordinary originality that distinguishes his approach. In comparing the two different ways of addressing the subject, again, the example of the general theory of relativity is helpful. Einstein himself pursued two different strategies, between which he vacillated, but which finally turned out to be complementary to each other. The first can be called the physical strategy and the other the mathematical strategy. ${ }^{29}$ The physical strategy was disproportionately more laborious, proceeding from the familiar Newtonian law of gravity and attempting to link it with the insights of the equivalence principle through cautious generalizations, occasionally going astray. The mathematical strategy was the apparently more direct one, proceeding from a sophisticated mathematical formulation of these new insights and attempting, inversely, to build a bridge to the tried-and-true Newtonian theory. However, it initially proved quite difficult to introduce the new mathematical relations into the context of the familiar physical concepts. Overall the emergence of the general theory of relativity presents itself as the result of a conflict-ridden interaction between the development of a mathematical formalism and the formation of physical concepts. The different components of knowledge that flowed into the theory grew together on the substrate of this interaction.

Initially it appears that Schrödinger, with his almost graphic image of waves, followed a physical strategy, while Heisenberg, with his impenetrable matrix mechanics, which consciously disregarded the idea of concrete atomic models, preferred a mathematical strategy. But upon closer examination, the opposite is true! The path Heisenberg chose, and which Bohr, Kramers, Born, van Vleck and others before him had blazed, more resembles the physical strategy of Einstein. What guided knowledge here was the correspondence principle, for which, as we saw, great,

\footnotetext{
${ }^{28}$ See the discussion of Ritz's combination principle in (Hund, 1967, p. 54) and (Darrigol, 1992b, p. 122).

${ }^{29}$ See (Renn, 2007).
} 
occasionally fruitless efforts were undertaken to generalize and "sharpen" it step by step, until this path ultimately flowed into Heisenberg's work of re-interpretation. The mathematical importance of the theory thus achieved was initially as unclear as the theoretical approaches Einstein had developed alongside his physical strategy. Max Born was the first to recognize that Heisenberg's computational rules corresponded to the matrix operations long known to mathematics (Born and Jordan, 1925). The physical meaning of Heisenberg's theory, in contrast, was secured from the outset by its origination in the generalization of the solution of specific physical problems like that of dispersion. ${ }^{30}$

In contrast to this, Schrödinger's path to his wave mechanics was a solo home run, achieved apparently without attending to concrete physical problems in order to guide his discovery - with the exception of gas theory (Hanle, 1971, 1975) and the touchstone of any acceptable comprehensive quantum theory, the spectrum of the hydrogen atom. Although Schrödinger's wave equation awakened the hope that quantum problems could be solved from that point on using descriptive concepts like oscillations and standing waves, the route to its discovery is rather reminiscent of Einstein's mathematical strategy. With one fell swoop, Schrödinger's wave equation embodied the keen conceptual insight into the wave nature of matter. Similarly, the Riemann tensor written down by Einstein, assisted by his mathematician friend Marcel Grossmann, stood for the revolutionary insight that gravity could be conceived of as a curvature of time and space. But how such insights could be connected with the established knowledge of classical physics, be it about planetary or electron orbits, still remained to be seen. At the same time, the solution of these questions was also linked with the challenge of interpreting the surprising further consequences of such mathematical formulations in terms of physics, often at the cost of giving up or modifying established concepts. In the case of the Schrödinger equation, hopes were soon dashed that it could be interpreted within a descriptive approach. ${ }^{31}$ Instead it had to give way to the fully novel idea that the solutions of this equation were connected with statements about the probability of the results of certain operations to measure physical systems. ${ }^{32}$

But how was Schrödinger, in view of the unexpected consequences of his equation, and initially in the absence of further physical applications, at all able to presume that his wave equation would offer a foundation for the solution of quantum problems? His notebooks reveal that he was by no means satisfied with a brief derivation along the lines sketched above, which merely inserted the de Broglie relation into a classical wave equation. First of all, he had set himself the more ambitious goal of deriving a relativistic wave equation of matter. This was more than plausible, considering de Broglie's approach, which was motivated by the

\footnotetext{
${ }^{30}$ See (Duncan and Janssen, 2007a,b)

${ }^{31}$ For Schrödinger's rooting in the descriptive tradition of Boltzmann and others, see (Wessels, 1983).

${ }^{32}$ This interpretation goes back to (Born, 1926a,b). For the history of the ensuing debates, see, e.g., (Jammer, 1966; Beller, 1999). For Schrödinger's later stance in the ensuing debate, see (Bitbol, 1996).
} 
theory of relativity and $E=m c^{2}$, and also opened up perspectives that lay beyond the non-relativistic quantum mechanics of the agenda pursued by Heisenberg and his colleagues. Yet Schrödinger did not succeed in deriving such a relativistic wave equation of the hydrogen spectrum including the Sommerfeld fine-structure. In the end, in (Schrödinger, 1926b,c) he reverted to a non-relativistic wave equation, which then did yield the correct spectrum.

Yet how could this equation be convincing if the relativistic generalization it suggested - it necessitated - led to untenable results? What is more, the derivation of the hydrogen spectrum remained an isolated result at first. Of course, before publishing his first paper Schrödinger attempted to derive other physical effects as well, like the Stark effect, that is, the shifting and splitting of spectral lines in an electrical field, but such attempts were not crowned with success until later. ${ }^{33}$ So how could he be sure that the correspondence of his result with the known spectrum of hydrogen was anything more than a fluke? As we saw, Heisenberg had his "sharpened" correspondence principle to secure the connection to the established results of classical physics. What could take the place of this reassurance for Schrödinger? Merely proposing a wave equation did not achieve the task of linking old and new knowledge.

At this juncture Schrödinger was aided by an insight of classical physics that seemed incidental, but which was to play a role in linking his wave mechanics with classical mechanics similar to that of Einstein's equivalence principle for connecting classical mechanics with the general theory of relativity. In the early 19th century Hamilton had shown that classical mechanics and ray optics could be formulated in analogous mathematical terms (Hamilton, 1833, 1837). Schrödinger had been familiar with this optical-mechanical analogy long before turning to the problem of wave mechanics. ${ }^{34}$ Now it became an indispensable instrument for him to establish a connection between his theory and classical mechanics as well as the older quantum theory. Since the early 19th century the wave theory of light had prevailed, as this was the only way to explain phenomena like diffraction and interference. Nevertheless, ray optics remained a good approximation of reality for certain circumstances, namely for wavelengths that are short with respect to the dimensions of optical instruments. Thus for Schrödinger it seemed logical to conceive of the relation between his wave mechanics and classical mechanics in a similar way to the relation between wave optics and ray optics: just as ray optics was simply an approximation to the "real" wave optics, corpuscular mechanics was a mere approximation to an underlying, more fundamental "wave" mechanics. At the same time, this approach solved the problem that had been covered by the correspondence principle in Heisenberg's approach.

In one of his notebooks (see Fig. 9) Schrödinger attempted to derive his wave equation directly from an expression that plays a key role in connecting classical mechanics and ray optics, and at the same time supplied the starting point of the

\footnotetext{
${ }^{33}$ This happened in May 1926, in (Schrödinger, 1926e).

${ }^{34}$ See (Joas and Lehner, 2009).
} 


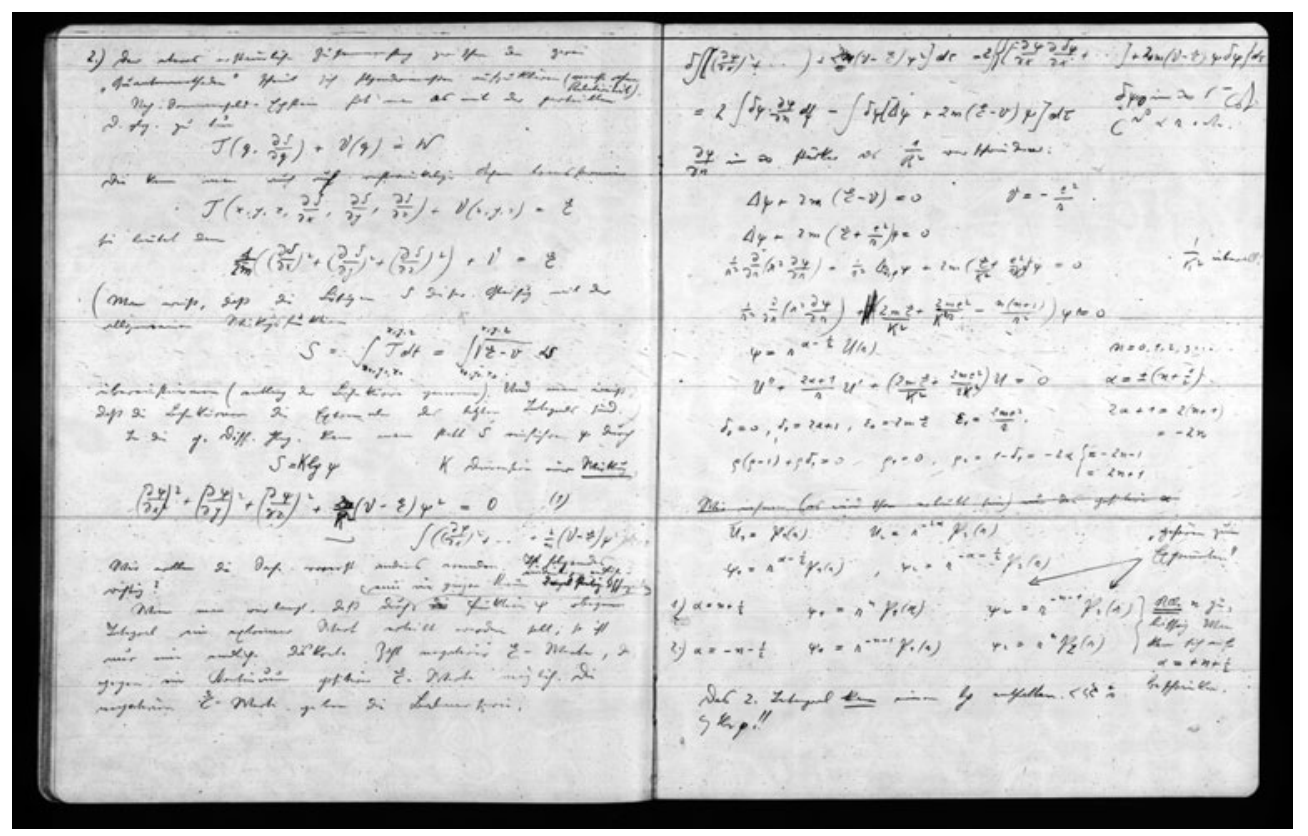

Abbildung 9. Double page from Schrödinger's notebook that very probably served as the basis for his first communication on wave mechanics (Schrödinger, 1926b) and can thus be dated to late 1925 or early 1926. On an earlier page of this notebook, Schrödinger had proposed to reconsider "the old Hamiltonian analogy between optics and mechanics." On the present double page, he claimed to have found the "somewhat astonishing connection between the two "quantum methods'," probably referring to the Sommerfeld-Epstein procedure of the old quantum theory, which was based on the Hamilton-Jacobi equation, and his own. He attempted, in fact, to derive his wave equation from an ad hoc generalization of the Hamilton-Jacobi equation.

old quantum theory. ${ }^{35}$ This derivation was doomed to failure, however, for deriving wave optics from ray optics is just as impossible as deriving wave mechanics from an equation of classical mechanics. But a minor change to the mathematical conditions imposed on this expression meant that the desired wave equation actually was yielded; from this, in turn, approximation could be applied to attain classical physics.

In this manner Schrödinger had discovered a route, albeit a somewhat bumpy one, that linked his wave equation with the knowledge of classical mechanics and the old quantum theory, and ultimately made it the basis for introducing the Schrödinger equation in his first communication (Schrödinger, 1926b). Since the connection between this derivation and the optical-mechanical analogy was

\footnotetext{
${ }^{35}$ Archive for the History of Quantum Physics, reel 40, section 5, item 3.
} 


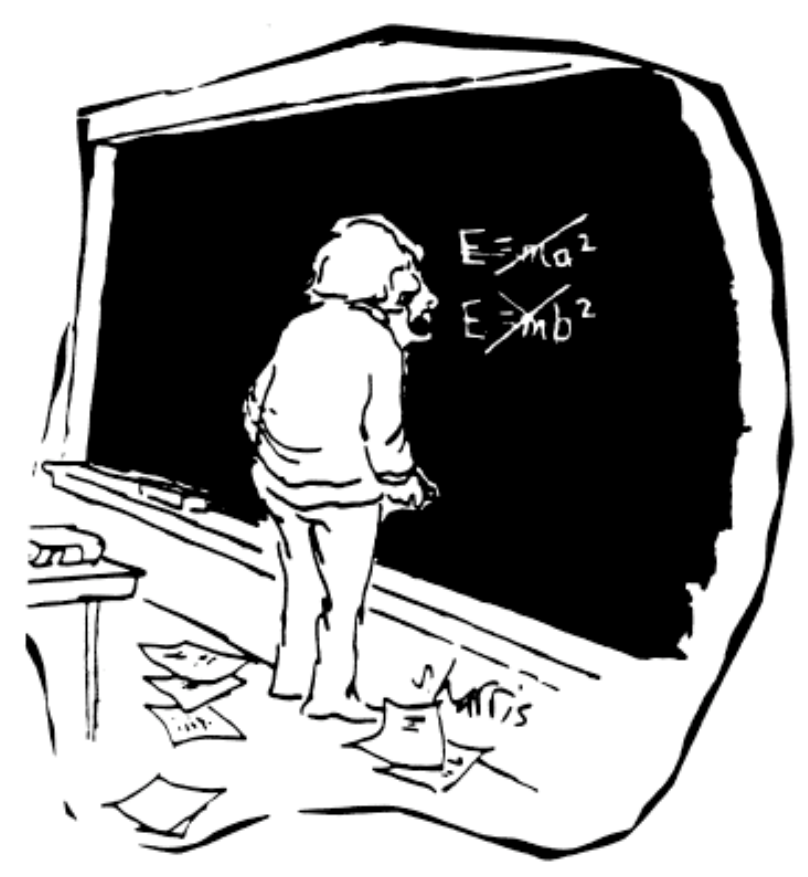

Abbildung 10. Cartoon by S. Harris. (C)ScienceCartoonsPlus.com

not made expressly there, its true purpose and meaning seemed mysterious, ${ }^{36}$ and probably would have remained concealed without close study of Schrödinger's notebooks and other sources that had previously eluded consideration (Joas and Lehner, 2009). Not until his second paper (Schrödinger, 1926c) did Schrödinger then elaborate on the optical-mechanical analogy, now that he himself, after completing the first paper, had comprehended how important it was for physics in establishing the connection between classical and wave mechanics.

So what was Schrödinger's path to wave mechanics? We started, somewhat provocatively, with the apparently simple character of the discovery of the Schrödinger equation, depicting it along the lines of the famous caricature in which Einstein stands thoughtfully in front of a blackboard on which the formulae $E=m a^{2}$ and $E=m b^{2}$ have already been rejected and crossed out (Fig. 10.). Does it really take a genius now to arrive at the idea that the right solution is $E=m c^{2}$ ? The wit of this caricature is apparently that the rejected solutions already contain the ingenious thought that there is a connection between energy and mass, whereby the question as to how this connection can be justified is entirely absent. By contrast, in the case of the Schrödinger equation, we saw that it was the recognition of the

${ }^{36}$ See, e.g., (Kragh, 1982; Wessels, 1983). 
connection between his new theory and the old mechanics that made his solution so ingenious. Incidentally, that was Schrödinger's own estimation even as early as $1926:^{37}$

The power of the present attempt-if I may be permitted to pass judgement - lies in the guiding physical aspect which builds the bridge between the macroscopic and the microscopic mechanical events, and which makes comprehensible the formally different method of treatment they require.

We further saw that the twin paradox of the history of quantum mechanics, its parallel emergence as matrix and as wave mechanics, can be explained genetically. Both theories emerged from a transformation of the knowledge of classical physics, in which Planck's relation between energy and frequency was to be integrated. Both theories include findings about the connection between classical and quantum physics. In Schrödinger's formulation of wave mechanics, the optical-mechanical analogy plays the same role that the correspondence principle plays in leading to matrix mechanics. The two routes are complements of each other. Schrödinger proceeded from what was in principle a familiar mathematical formulation, whose consequences for physics were sounded out afterward, while Heisenberg obtained his theory from a generalization of the solution to concrete physical problems and then found a satisfactory mathematical formulation.

The great historian of science Thomas S. Kuhn was one of the most knowledgeable experts of the history of quantum physics (Kuhn, 1962, 1982, 1987). Yet in his treatment of this history his concept of scientific revolution crumbles a bit, dissolving into many smaller paradigm shifts. The picture sketched here leads to a different understanding of this great breakthrough in the history of science. This breakthrough can be understood properly only if we keep in mind that the scientific knowledge of quantum theory is part of a more comprehensive knowledge system of physics, which already had been developing for a millennium at the time our story was taking place. There is probably no greater success for a physicist than recognition for having pointed out a new direction in this tremendous history of human development. Erwin Schrödinger deserves this recognition.

\section{Acknowledgments}

I am grateful to Professor Wolfgang L. Reiter for providing the opportunity to present these thoughts on the occasion of the Erwin Schrödinger-Symposium 2011 in Vienna. I am very grateful also to Ruth and Arnulf Braunizer for sharing with me their memories of Erwin Schrödinger, as well as for their generosity and hospitality

\footnotetext{
${ }^{37}$ Translated from (Schrödinger, 1926c, p. 514): "Die Stärke des vorliegenden Versuches - wenn es mir erlaubt ist, darüber ein Urteil zu sagen - liegt in dem leitenden physikalischen Gesichtspunkt, welcher die Brücke schlägt zwischen dem makroskopischen und dem mikroskopischen mechanischen Geschehen, und welcher die äußerlich verschiedene Behandlungsweise, die sie erfordern, verständlich macht."
} 
on several occasions. Susan Richter and Christian Joas have prepared the English version of this text. I want to express my particular gratitude to Christian Joas for the substantial investment of his time and effort to enrich and edit this text, as well as for the many productive discussions on Schrödinger, in Alpbach as well as in Berlin. This paper is an outcome of the joint work on Schrödinger's notebooks with Christian Joas and Christoph Lehner who also provided many helpful suggestions. I am grateful also to Alexander S. Blum for helpful insights. The final editing of this paper is due to Lindy Divarci.

\section{Literatur}

Beller, M. (1999). Quantum Dialogue. Chicago: University of Chicago Press.

Bitbol, M. (1996). Schrödinger's Philosophy of Quantum Mechanics. Dordrecht: Kluwer.

Born, M. (1924). Über Quantemechanik. Zeitschrift für Physik, 26, 379-395.

Born, M., Jordan, P. (1925). Zur Quantenmechanik. Zeitschrift für Physik, 34, 858-888.

Born, M., Heisenberg, W., Jordan, P. (1926). Zur Quantenmechanik. II. Zeitschrift für Physik, 35, 557-615.

Born, M. (1926a). Zur Quantenmechanik der Stoßvorgänge (Vorläufige Mitteilung). Zeitschrift für Physik, 37, 863-867.

Born, M. (1926b). Quantenmechanik der Stoßvorgänge. Zeitschrift für Physik, 38, 803-82\%.

Bohr, N. (1913). On the constitution of atoms and molecules. Part I. Philosophical Magazine, Series 6, 26, 1-25.

Broglie, L. de (1924). Recherche sur la théorie des quanta. Thèse, Paris: Masson \& Cie.

Buchwald, J. Z. (1989). The Rise of the Wave Theory of Light: Optical theory and Experiment in the Early Nineteenth Century. Chicago: University of Chicago Press.

Büttner, J., Renn, J., Schemmel, M. (2003). Exploring the Limits of Classical Physics. Planck, Einstein and the Structure of a Scientific Revolution. Studies in History and Philosophy of Modern Physics Part B: Studies In History and Philosophy of Modern Physics, 34:1, 37-59.

Darrigol, O. (1986). The origin of quantized matter waves, Historical Studies in the Physical and Biological Sciences, 16, 197-253.

Darrigol, O. (1992a). Schrödinger's Statistical Physics and some Related Themes. In M. Bitbol and O. Darrigol (Eds.), Erwin Schrödinger: Philosophy and the Birth of Quantum Mechanics (pp. 237-276). Gif-sur-Yvette: Editions Frontières.

Darrigol, O. (1992b). From c-Numbers to q-Numbers. The Classical Analogy in the History of Quantum Theory. Berkeley: University of California Press.

Duncan, T., Janssen, M. (2007). On the verge of Umdeutung in Minnesota: Van Vleck and the correspondence principle. Part one. Archive for the History of the 
Exact Sciences, 61, 553-624.

Duncan, T., Janssen, M. (2007). On the verge of Umdeutung in Minnesota: Van Vleck and the correspondence principle. Part two. Archive for the History of the Exact Sciences, 61, 625-671.

Einstein, A. (1905). Über einen die Erzeugung und die Verwandlung des Lichtes betreffenden heuristischen Gesichtspunkt. Annalen der Physik, 17, 132-148.

Einstein, A. (1916a). Strahlungs-Emission und -Absorption nach der Quantentheorie. Deutsche Physikalische Gesellschaft. Verhandlungen, 18, 318-323.

Einstein, A. (1916b). Zur Quantentheorie der Strahlung. Physikalische Gesellschaft Zürich. Mitteilungen, 18, 47-62. Also published in: Physikalische Zeitschrift, 18 (1917), 121-128.

Einstein, A. (1924). Quantentheorie des einatomigen idealen Gases. Sitzungsberichte der Preussischen Akademie der Wissenschaften. Physikalisch-Mathematische Klasse, 22, 261-267.

Feynman, R. P., Leighton, R. B., Sands, M. L. (1965). The Feynman Lectures on Physics. Vol. III. Reading, Massachusetts: Addison-Wesley.

Gerber, J. (1969). Geschichte der Wellenmechanik. Archive for the History of the Exact Sciences, 5, 349-416.

Hamilton, W. R. (1833). On a General Method of Expressing the Paths of Light, and of the Planets, by the Coefficients of a Characteristic Function. In Conway, A. W., Synge, J. L. (Eds.), The Mathematical Papers of Sir William Rowan Hamilton, Volume I: Geometrial Optics (p. 311-332). Cambridge: Cambridge University Press.

Hamilton, W. R. (1837). Third Supplement to an Essay on the Theory of Systems of Rays. In Conway, A. W., Synge, J. L. (Eds.), The Mathematical Papers of Sir William Rowan Hamilton, Volume I: Geometrial Optics (p. 164-293). Cambridge: Cambridge University Press.

Hanle, P. A. (1971). The coming of age of Erwin Schrödinger: His quantum statistics of ideal gases. Archive for the History of the Exact Sciences, 17, 165-192.

Hanle, P. A. (1975). Erwin Schrödinger's Statistical Mechanics, 1912-1925. PhD Dissertation, Stanford University.

Hanle, P. A. (1977). Erwin Schrödinger's reaction to Louis de Broglie's thesis on the quantum theory. Isis, 68, 606-609.

Heilbron, J. L., Kuhn, T. S. (1969). The Genesis of the Bohr atom. Historical Studies in the Physical Sciences, 1, 211-290.

Heisenberg, W. (1925). Über quantentheoretische Umdeutung kinematischer und mechanischer Beziehungen. Zeitschrift für Physik, 33, 879-893.

Hoffmann, D. (1984). Erwin Schrödinger. Biographien hervorragender Naturwissenschaftler, Techniker und Mediziner; Vol. 66. Leipzig: Teubner.

Hund, F. (1967). Geschichte der Quantentheorie. Mannheim: Bibliographisches Institut.

Jammer, M. (1966). The Conceptual Development of Quantum Mechanics. New York: McGraw-Hill.

Joas, C., Lehner, C. (2009). The classical roots of wave mechanics: Schrödinger's 
transformations of the optical-mechanical analogy. Studies in History and Philosophy of Modern Physics, 40, 338-351.

Jungnickel, C., McCormmach, R. (1986). Intellectual Mastery of Nature: Theoretical Physics from Ohm to Einstein, Volume 2. Chicago: University of Chicago Press.

Kragh, H. (1982). Erwin Schrödinger and the Wave Equation: The Crucial Phase. Centaurus, 26, 154-19\%.

Kronig, R. (1960). The Turning Point. In: M. Fierz and V. F. Weisskopf (Eds.). Theoretical Physics in the Twentieth Century. A Memorial Volume to Wolfgang Pauli. New York: Interscience.

Kubli, F. (1970). Louis de Broglie und die Entdeckung der Materiewellen. Archive for History of Exact Sciences, 7, 26-68.

Kuhn, T. S. (1962). The Structure of Scientific Revolutions. Chicago: University of Chicago Press.

Kuhn, T. S. (1982). Was sind wissenschaftliche Revolutionen?: 10. WernerHeisenberg-Vorlesung gehalten in München-Nymphenburg am 24. Febr. 1981. München-Nymphenburg: Carl-Friedrich-von-Siemens-Stiftung.

Kuhn, T. S. (1987). Black-Body Theory and the Quantum Discontinuity, 1894-1912. Chicago: University of Chicago Press.

Ludwig, G. (1969). Wellenmechanik. Einführung und Originaltexte. Berlin: Akademie-Verlag.

McCormmach, R. (1970). H. A. Lorentz and the electromagnetic view of nature. Isis, 61, 459-497.

Mehra, J., Rechenberg, H. (1987a). The Historical Development of Quantum Theory, Volume 5, Erwin Schrödinger and the Rise of Wave Mechanics, Part 1, Schrödinger in Vienna and Zürich, 1887-1925. New York: Springer.

Mehra, J., Rechenberg, H. (1987b). The Historical Development of Quantum Theory, Volume 5, Erwin Schrödinger and the Rise of Wave Mechanics, Part 2, The Creation of Wave Mechanics: Early Response and Applications, 1925-1926. New York: Springer.

von Meyenn, K. (2011). Eine Entdeckung von ganz außerordentlicher Tragweite: Schrödingers Briefwechsel zur Wellenmechanik und zum Katzenparadoxon. Heidelberg: Springer.

Moore, W. J. (1989). Schrödinger: Life and Thought. Cambridge: Cambridge University Press.

Moore, W. J. (1994). A Life of Erwin Schrödinger. Cambridge: Cambridge University Press.

Muller, F. A. (1997a). The equivalence myth of quantum mechanics. Part I. Studies In History and Philosophy of Science Part B: Studies In History and Philosophy of Modern Physics, 28, 35-61.

Muller, F. A. (1997b). The equivalence myth of quantum mechanics. Part II. Studies In History and Philosophy of Science Part B: Studies In History and Philosophy of Modern Physics, 28, 219-24\%.

Muller, F. A. (1999). The Equivalence Myth of Quantum Mechanics (Addendum). 
Studies In History and Philosophy of Science Part B: Studies In History and Philosophy of Modern Physics, 30, 543-545

von Neumann, J. (1932). Mathematische Grundlagen der Quantenmechanik. Berlin: Springer.

Pauli, W. (1926). Über das Wasserstoffspektrum vom Standpunkt der neuen Quantenmechanik. Zeitschrift für Physik, 36, 336-363.

Pauli, W. (1979). Scientific Correspondence with Bohr, Einstein, Heisenberg a.o., Volume I: 1919-1929. Edited by A. Hermann, K. v. Meyenn, V. F. Weisskopf. New York: Springer.

Perovic, S. (2008). Why Were Matrix Mechanics and Wave Mechanics Considered Equivalent? Studies in History and Philosophy of Modern Physics, 39, 444-461.

Renn, J. (2006). Auf den Schultern von Riesen und Zwergen. Einsteins unvollendete Revolution. Weinheim: Wiley.

Renn, J. (Ed.) (2007). The Genesis of General Relativity. 4 Volumes. Dordrecht: Springer.

Schrödinger, E. (1926a). Zur Einsteinschen Gastheorie. Physikalische Zeitschrift, 27, 95-101.

Schrödinger, E. (1926b). Quantisierung als Eigenwertproblem (Erste Mitteilung). Annalen der Physik, 79, 361-376.

Schrödinger, E. (1926c). Quantisierung als Eigenwertproblem (Zweite Mitteilung). Annalen der Physik, 79, 489-52\%.

Schrödinger, E. (1926d). Über das Verhältnis der Heisenberg-Born-Jordanschen Quantenmechanik zu der meinen. Annalen der Physik, 79, 734-756.

Schrödinger, E. (1926e). Quantisierung als Eigenwertproblem (Dritte Mitteilung). Annalen der Physik, 80, 437-490.

Schrödinger, E. (1926f). Quantisierung als Eigenwertproblem (Vierte Mitteilung). Annalen der Physik, 81, 109-139.

Scott, W. T. (1967). Erwin Schrödinger. An Introduction to His Writings. Amherst: University of Massachusetts Press.

Sommerfeld, A. (2004). Wissenschaftlicher Briefwechsel, Band 2: 1919-1951. Eckert, M. and Märker, K. (Eds.). Berlin: GNT-Verlag.

Wessels, L. (1979). Schrödinger's route to wave mechanics. Studies in History and Philosophy of Science, 10, 311-340.

Wessels, L. (1983). Erwin Schrödinger and the Descriptive Tradition. In R. Aris, H. T. Davis, and R. Stuewer (Eds.), Springs of Scientific Creativity: Essays on Founders of Modern Science (pp. 254-278). Minneapolis: University of Minnesota Press.

Wheaton, B. R. (1983). The Tiger and the Shark: Empirical Roots of Wave-Particle Dualism. Cambridge: Cambridge University Press.

Wünschmann, A. (2007). Der Weg zur Quantenmechanik. Kirchheimbolanden: Studien-Verlag Wünschmann. 



\title{
MAX-PLANCK-INSTITUT FÜR WISSENSCHAFTSGESCHICHTE
}

\author{
Max Planck Institute for the History of Science
}

Preprints since 2011 (a full list can be found at our website)

411 Henning Schmidgen \& Urs Schoepflin (eds.) Hans-Jörg Rheinberger : a Bibliography

412 Renate Wahsner \& Horst-Heino v. Borzeszkowski Erkenntnis statt Erbauung: Hegel und das naturwissenschaftliche Denken der Moderne

413 Mirjam Brusius From photographic science to scientific photography: Photographic experiments at the British Museum around 1850

414 Viktor J. Frenkel Professor Friedrich Houtermans - Arbeit, Leben, Schicksal. Biographie eines Physikers des zwanzigsten Jahrhunderts. Herausgegeben und ergänzt von Dieter Hoffmann, unter Mitwirkung von Mary Beer

415 Ilana Löwy (ed.) Microscope Slides - Reassessing a Neglected Historical Ressource

416 André L. Blum, John Michael Krois und Hans-Jörg Rheinberger (Hrsg.) Verkörperungen

417 Pietro Daniel Omodeo Sixteenth Century Professors of Mathematics at the German University of Helmstedt. A Case Study on Renaissance Scholarly Work and Networks

418 Peter Schöttler \& Hans-Jörg Rheinberger (éds.) Marc Bloch et les crises du savoir

419 Albert Presas i Puig (ed.) A Comparative Study of European Nuclear Energy Programs

420 Mathias Grote \& Max Stadler (eds.) Membranes Surfaces Boundaries Interstices in the History of Science, Technology and Culture

421 Frank W. Stahnisch The emergence of Nervennahrung: Nerves, mind and metabolism in the long eighteenth century

422 Pietro Daniel Omodeo, Irina Tupikova Aristotle and Ptolemy on Geocentrism: Diverging Argumentative Strategies and Epistemologies (TOPOI - Towards a Historical Epistemology of Space)

423 Han F. Vermeulen Linguistik und Völkerkunde - der Beitrag der historisch-vergleichenden Linguistik von G.W. Leibniz zur Entstehung der Völkerkunde im 18. Jahrhundert [Leicht erweiterte Fassung des Working Papers No. 133 aus dem MPI for Social Anthropology]

424 Alfred Gierer Mit Schiller gegen den „Egoismus der Vernunft“. Zeitübergreifende Gedanken zur Natur des Menschen

425 Annette Vogt Die Berliner Humboldt-Universität von 1945/1946 bis 1960/1961

426 Klaus Geus, Martin Thiering (eds.) Common Sense Geography and Mental Modelling

427 Renate Wahsner Kann eine moderne Naturphilosophie auf Hegelsche Prinzipien gegründet werden? Spekulatives und naturwissenschaftliches Denken

428 Stefano Bordoni Widening the Scope of Analytical Mechanics Duhem's third pathway to Thermodynamics

429 Pietro Daniel Omodeo Copernicus in the Cultural Debates of the Renaissance: Reception, Legacy, Transformation [Part | \& II]

430 Mark Geller \& Klaus Geus (eds.) Productive Errors: Scientific Concepts in Antiquity (TOPOI - Dahlem Seminar for the History of Ancient Sciences)

431 Klaus Gottstein The Amaldi Conferences. Their Past and Their Potential Future

432 Mikuláš Teich The Scientific Revolution Revisited 
433 Lorraine Daston \& Jürgen Renn (Hrsg.) Festkolloquium für Hans-Jörg Rheinberger Beiträge zum Symposium am 24. 1. 2011 im Max-Planck-Institut für Wissenschaftsgeschichte

434 Conference Epistemology and History. From Bachelard and Canguilhem to Today's History of Science

435 Jens Høyrup Sanskrit-Prakrit interaction in elementary mathematics as reflected in Arabic and Italian formulations of the rule of three - and something more on the rule elsewhere

436 Jens Høyrup A hypothetical history of Old Babylonian mathematics: places, passages, stages, development 